\title{
Disease prevalence and grade repetition among adolescents in South Africa: Is there any relationship?
}

\author{
N De Wet, PhD; S Frade, MA \\ Demography and Population Studies, Schools of Public Health and Social Sciences, Faculties of Health Sciences and Humanities, University of \\ the Witwatersrand, Johannesburg, South Africa
}

Corresponding author: $N$ de Wet (nicole.dewet@wits.ac.za)

\begin{abstract}
Background. A universal goal of public health is to ensure that adolescents have a healthy transition to adulthood. In developing countries, a host of social, economic and political factors inhibit this from happening. The results of these challenges include an increasing disease prevalence among an age group (10 - 19-year-olds) that should be healthy.

Objectives. The purpose of this study is to identify the most prevalent diseases and assess the relationship between disease and grade repetition among adolescents in South Africa (SA), and to assess the impact of disease on grade repetition.

Methods. Data from the SA General Household Surveys (2009 - 2016) were analysed, and both adolescent (10 - 19 years) sexes from all geographical and racial groups were included. Frequencies, percentages and rates of infectious, non-communicable diseases (NCDs) and mental health outcomes were estimated. The relationship between disease and grade repetition was determined using logistic regression.

Results. Infectious diseases, NCDs and mental illnesses are increasing in adolescents over time. In urban areas, rates of NCDs are higher than those of infectious diseases, while in rural areas a high burden of infectious disease persists. Among adolescents who repeated a grade, $7.07 \%$ had an infectious disease. In addition, infectious disease (odds ratio (OR) 1.17, $p<0.05$ ), younger adolescents, 15 - 19 -year-olds (OR $1.52, p<0.05)$ and urban residence (OR 1.12, $p<0.05)$ are associated with increased likelihood of grade repetition.

Conclusion. Policies and programmes in SA which address the health of adolescents need to be more aware of the disease prevalence among school pupils in the country. Prolonged disease occurrences are contributing to the slow school progression and eventual matriculation of pupils.
\end{abstract}

S Afr J Child Health 2018;12(2 Suppl 1):S67-S70. DOI:10.7196/SAJCH.2018.v12i2.1504

Education, employment and health are all key factors in the successful transition to adulthood. Adolescents in sub-Saharan African (SSA) countries face numerous problems relating to the attainment of education and employment, including structural difficulties, gender imbalances in their access and poverty. ${ }^{[1,2]}$ Worst of all is the effect that poor health outcomes have on school completion and retaining employment. ${ }^{[3-5]}$ However, adolescents are vital to the social and economic development of SSA countries, and poor health during adolescence in turn compromises adult health, and leads to early mortality. For this reason, the health of adolescents is a top priority and essential to unlocking future sustainable development.

In South Africa (SA), adolescents comprise $18.5 \%$ of the total population, and secondary school gross enrolment is high, at $90 \%{ }^{[6]}$ Should these adolescents successfully transition to adulthood, the country would reap the benefits of a large and skilled labour force. However, adolescents in SA face problems in their access to health services, and are affected by HIV/AIDS, crime and violence in their households and communities, and these challenges all contribute to a compromised transition to adulthood. ${ }^{[7-9]}$ In addition, adolescents are not a completely autonomous group, and require the assistance of parents and caregivers in achieving optimal health and developmental progress.

An important part of the transition to adulthood is the completion of schooling. A number of factors contribute to school dropout rates, including grade repetition. Repeating a school grade is shown to have negative mental and emotional consequences for adolescents, with research showing that learners tend to feel depressed and have low self-esteem when having to repeat a grade at school. ${ }^{[10,11]}$ Recent research shows that as many as $52 \%$ of school learners in SA repeat a grade before reaching Grade $10 .{ }^{[12]}$ However, grade repetition might be inevitable if pupils are absent due to illness and disease, which is probable, because $5.3 \%$ of all youth in the country have had a selfreported recent disease. ${ }^{[13]}$

The purpose of this paper is to examine the relationship between disease (infectious, non-communicable and mental) and grade repetition among adolescents in SA. This is important for healthcare prevention and intervention programmes, as well as for education planning to cater for the needs of adolescents with diseases.

\section{Methods}

The study uses data from the nationally representative General Household Survey (GHS) for the years 2009 - 2016. The GHS is an annual cross-sectional survey. Data from 2009 to 2016 were pooled to increase the sample size. The survey collects demographic, health and socioeconomic data from households in all nine provinces of SA. Data are also freely available to use from the Statistics SA website.

This study analyses a sample of 14830 adolescents, 10 - 19 years old, who repeated a grade in school. Grade repetition is the outcome of interest in this study, and is measured by the question in the survey 'Have you repeated a grade at school?', to which respondents answered 'yes' or 'no. The variable remains binary in this study, with yes (1) and no (0) responses.

Specific infectious diseases included are positive (yes) responses to any respondents having any of the following: acute respiratory infections (ARIs), tuberculosis (TB), diarrhoea, and HIV/AIDS or other sexually transmitted infections. For non-communicable diseases (NCDs), positive (yes) responses from respondents to having asthma, hypertension, diabetes and cancer are included. For mental illness, positive responses (yes) to the question 'Have you been diagnosed with a mental illness?' are included. 
Control variables in the study include sex (male or female), race (black, coloured, Indian or white), place of residence (urban or rural), relationship to head of household and the mother being part of the household.

Frequencies, percentages, rates (per 10 000) and proportional mortality ratios (PMRs) were used to describe the sample of adolescents. Logistic regression models showing odds ratios (ORs) were used to quantify the relationship between disease prevalence and grade repetition.

\section{Results}

Fig. 1 shows that, over time, infectious diseases remained the most prevalent cause of morbidity among adolescents in SA, and throughout the survey period, adolescent girls were more affected than boys. NCD rates among boys were higher than those among

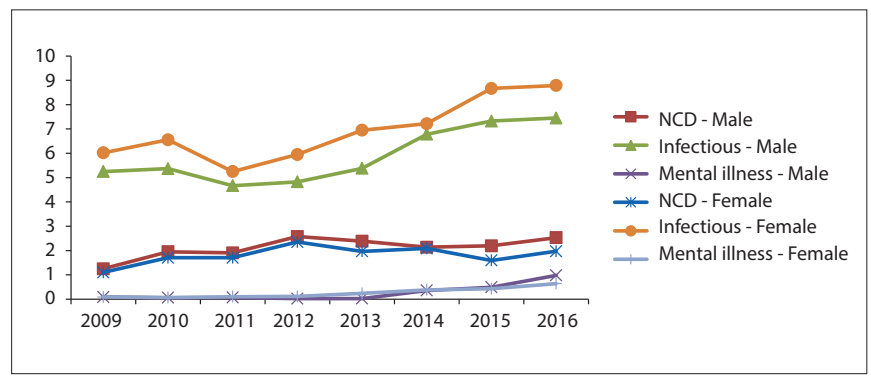

Fig. 1. Trends in rates of disease prevalence among adolescents, by sex, from 2009 to 2016. girls, and the trend was consistent over the period. Lastly, mental illness was low, at less than $1 \%$ for boys and girls over the period, but there is evidence to suggest that it is increasing.

Table 1 shows the rates of specific infectious, non-communicable and mental health diseases per 10000 in select characteristics of the sample. Asthma is the leading NCD, and ARI is the leading infectious disease among adolescents in SA. Hypertension (14.52 v.7.49), diabetes (16.90 v. 13.22), cancer (10.81 v. 8.96), diarrhoea (14.52 v. 7.49), HIV and other STIs (16.90 v. 13.22), TB (10.81 v. 8.96) and mental illness (23.87 v. 21.59$)$ are all higher among adolescent girls than boys. By race, black adolescents have higher rates of diarrhoea (24.72), HIV and other STIs (45.18), TB (24.38) and mental illness (20.63) than among other racial groups, while white adolescents have higher rates of hypertension (16.52), diabetes (55.31) and cancer (18.10). Adolescents in urban areas also have higher rates of all NCDs and mental illnesses than their rural counterparts, and rural residents have higher rates of diarrhoea (35.88), HIV and other STIs (30.11) and TB (22.10) than urban adolescents. Hypertension and all infectious disease rates are higher in households where mothers are not resident members and where adolescents head their households. Lastly, 14.53 per 10000 adolescents with hypertension had repeated a grade at school, and the rates of adolescents with diarrhoea, HIV and other STIs, and TB also repeating a grade at school were 23.48, 81.77 and 26.84, respectively.

ARI accounts for $67 \%$ of the disease burden among adolescents in SA (Table 2), followed by asthma, which accounts for $17.48 \%$ and $12.36 \%$ of all diseases among male and female adolescents, respectively, followed by HIV and other STIs, which account for

Table 1. Rates of disease (per 10000 adolescent population) by characteristics of adolescents, South Africa, 2009 - 2016

\begin{tabular}{|c|c|c|c|c|c|c|c|c|c|}
\hline \multirow[b]{2}{*}{ Characteristic } & \multicolumn{4}{|c|}{ NCD } & \multicolumn{4}{|c|}{ Infectious disease } & \multirow{2}{*}{$\begin{array}{l}\text { Mental } \\
\text { illness }\end{array}$} \\
\hline & Asthma & Hypertension & Diabetes & Cancer & ARI & Diarrhoea & HIV - STI & TB & \\
\hline \multicolumn{10}{|l|}{ Age group } \\
\hline $10-14(50.2 \%)$ & 127.31 & 6.12 & 13.58 & 10.90 & 571.78 & 24.71 & 44.63 & 22.16 & 20.07 \\
\hline $15-19(49.8 \%)$ & 109.44 & 15.91 & 16.54 & 8.85 & 499.43 & 23.24 & 34.31 & 24.45 & 25.40 \\
\hline \multicolumn{10}{|l|}{ Sex } \\
\hline Male (50.12\%) & 133.54 & 7.49 & 13.22 & 8.96 & 133.54 & 7.49 & 13.22 & 8.96 & 21.59 \\
\hline Female (49.88\%) & 103.21 & 14.52 & 16.90 & 10.81 & 103.21 & 14.52 & 16.90 & 10.81 & 23.87 \\
\hline \multicolumn{10}{|l|}{ Race } \\
\hline Black (83.27\%) & 93.92 & 10.37 & 10.42 & 9.24 & 492.22 & 24.72 & 45.18 & 24.38 & 20.63 \\
\hline Coloured (8.66\%) & 222.05 & 13.50 & 31.37 & 9.48 & 641.82 & 24.41 & 11.27 & 23.89 & 3.54 \\
\hline Indian/Asian (1.98\%) & 251.49 & 9.23 & 14.90 & 13.39 & 743.03 & 6.31 & 7.86 & 4.94 & 0.49 \\
\hline White $(6.09 \%)$ & 262.67 & 16.52 & 55.31 & 18.10 & 912.70 & 19.01 & 12.01 & 13.63 & 2.62 \\
\hline \multicolumn{10}{|l|}{ Place of residence } \\
\hline Urban (53.20\%) & 142.58 & 12.40 & 18.76 & 13.10 & 598.01 & 30.39 & 28.36 & 15.78 & 19.10 \\
\hline Rural (46.80\%) & 69.99 & 10.03 & 9.64 & 8.32 & 393.38 & 35.88 & 30.11 & 22.10 & 16.23 \\
\hline \multicolumn{10}{|c|}{$\begin{array}{l}\text { Relationship to mother part } \\
\text { of household }\end{array}$} \\
\hline Yes $(76.03 \%)$ & 133.43 & 9.65 & 18.66 & 10.34 & 567.78 & 23.13 & 26.53 & 21.58 & 24.43 \\
\hline No $(23.97 \%)$ & 80.58 & 13.09 & 8.03 & 7.42 & 469.57 & 26.87 & 29.04 & 22.71 & 18.93 \\
\hline \multicolumn{10}{|l|}{$\begin{array}{l}\text { Relationship to head of } \\
\text { household }\end{array}$} \\
\hline Son/daughter (59.6\%) & 137.14 & 9.64 & 18.27 & 11.03 & 592.95 & 24.82 & 27.90 & 21.91 & 23.73 \\
\hline Head $(1.27 \%)$ & 89.68 & 33.60 & 3.70 & 9.47 & 849.89 & 40.90 & 40.08 & 21.35 & 30.56 \\
\hline Other $(39.13 \%)$ & 90.81 & 12.34 & 10.52 & 8.15 & 438.43 & 22.15 & 57.12 & 25.49 & 20.94 \\
\hline \multicolumn{10}{|l|}{ Repeat grade } \\
\hline Yes $(11.08 \%)$ & 128.33 & 14.53 & 12.28 & 7.81 & 557.09 & 23.48 & 81.77 & 26.84 & 15.80 \\
\hline No $(88.92 \%)$ & 169.19 & 9.28 & 17.46 & 14.05 & 592.99 & 20.56 & 48.36 & 21.86 & 17.27 \\
\hline
\end{tabular}


$4.81 \%$ (males) and $5.06 \%$ (females) of the disease burden. Mental illnesses are ranked 5 th among males, at $2.83 \%$ of diseases and 6th among females, at $2.86 \%$. Diabetes is the 7 th-highest-ranking disease among males and females alike, and hypertension is ranked 9th among male and 8th among female adolescents in the country.

Of all adolescents who repeated a grade, $7.07 \%$ had had an infectious disease, at $7.60 \%$ for girls, and $6.69 \%$ for boys (Fig. 2). Additionally, $1.63 \%$ of grade repetition comprised adolescents with NCDs; boys with NCDs (1.66\%) had higher grade repetition rates than did girls $(1.60 \%)$. Mental illnesses contributed $0.14 \%$ of grade repetition among boys, and $0.26 \%$ among girls.

Table 2. Disease rank and proportional mortality ratios (PMRs) by sex of the adolescents

\begin{tabular}{llll}
\hline & $\begin{array}{l}\text { All } \\
\text { Rank } \\
\text { (PMR), } \\
\boldsymbol{n}(\%)\end{array}$ & $\begin{array}{l}\text { Male } \\
\text { Rank } \\
\text { (PMR), } \\
\boldsymbol{n}(\%)\end{array}$ & $\begin{array}{l}\text { Female } \\
\text { Rank } \\
\text { (PMR), } \\
\boldsymbol{n}(\%)\end{array}$ \\
\hline ARI & $1(67)$ & $1(65.56)$ & $1(68.33)$ \\
Asthma & $2(14.81)$ & $2(17.48)$ & $2(12.36)$ \\
HIV and other STIs & $3(4.94)$ & $3(4.81)$ & $3(5.06)$ \\
Diarrhoea & $4(3.00)$ & $6(2.57)$ & $4(3.39)$ \\
TB & $5(2.91)$ & $4(2.87)$ & $5(3.39)$ \\
Mental illness & $6(2.84)$ & $5(2.83)$ & $6(2.86)$ \\
Diabetes & $7(1.88)$ & $7(1.73)$ & $7(2.02)$ \\
Hypertension & $8(1.38)$ & $9(0.98)$ & $8(1.74)$ \\
Cancer & $9(1.24)$ & $8(1.17)$ & $9(1.29)$ \\
\multicolumn{2}{l}{ ARI = acute respiratory infection; STI $=$ sexually transmitted infection. }
\end{tabular}

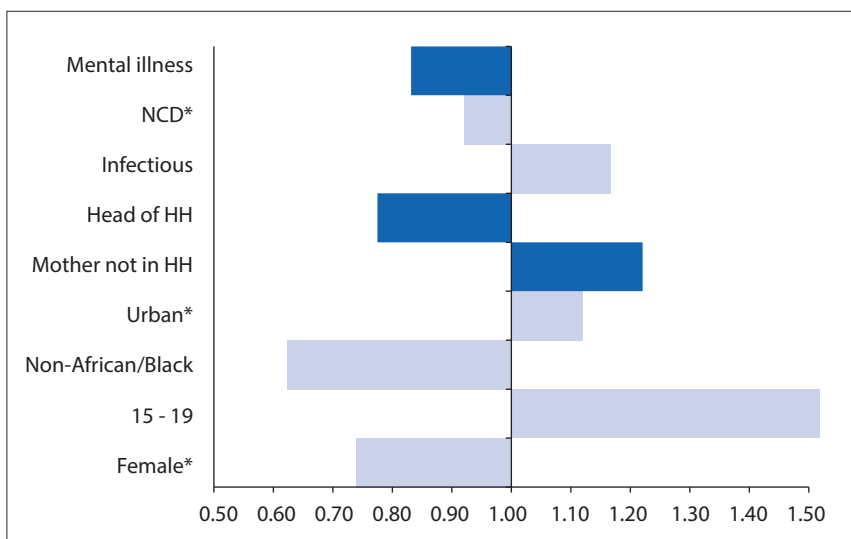

Fig. 2. Percentage distribution of repeat grade by type of disease and sex among adolescents. $(H H=$ household. $)$

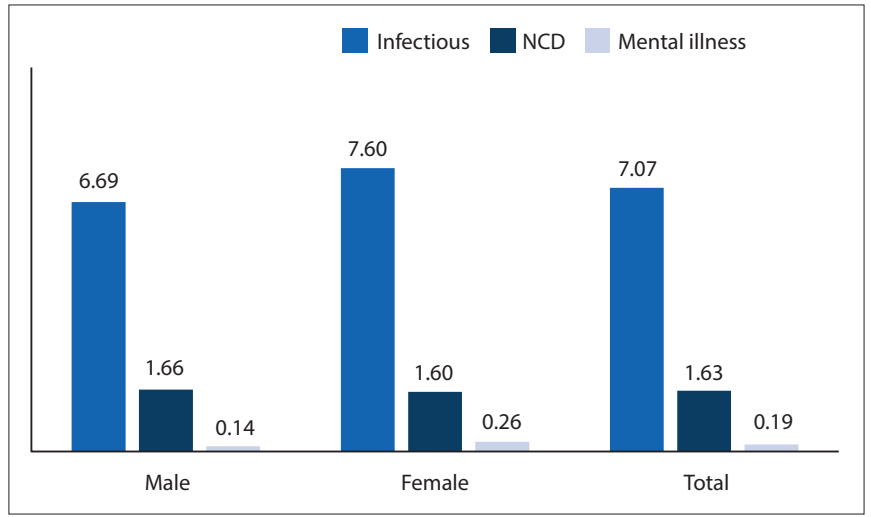

Fig. 3. Adjusted odds of grade repetition by adolescent characteristics and disease status. $\left({ }^{*}\right.$ Statistically significant $(p<0.05)$.)
Fig. 3 shows the ORs of grade repetition by disease status and select characteristics of adolescents. Girls (OR 0.74, $p<0.05$ ), nonblack ethnicity (OR $0.62, p<0.05$ ) and NCDs (OR 0.92, $p<0.05$ ) are less likely to be associated with repeating grades, with ORs $<1$. Adolescents aged $15-19$ years (OR 1.52, $p<0.05$ ), residing in urban areas (OR 1.12, $p<0.05)$ and with infectious disease (OR 1.17, $p<0.05)$ are more likely to repeat a grade at school. Mental illness, relationship to head of the household and the mother not being part of the household were not found to be statistically significant.

\section{Discussion}

The burden of disease compromises a healthy transition to adulthood. Disease and illness have direct health and longevity consequences, but also hinder personal development. The purpose of this study was to identify the most prevalent diseases among adolescents, and to examine the relationship between disease and grade repetitions at school. The study contributes to the literature on the topic by highlighting the varying contributions of infectious and non-communicable diseases, as well as mental illness, to the health and development profile of adolescents in SA. Previous studies have examined the determinants of disease outcomes, but have not examined how disease affects the success of transition to adulthood.

Disease among adolescents is affecting school progression through grade repetition. Infectious and non-communicable disease prevalence is associated with grade repetition among 10 - 19-yearolds. Existing literature from other countries confirms that disease is associated with slow school progression. ${ }^{[14-16]}$ This has implications at an individual and a population level. At a population level, the more learners who repeat grades, the slower the output of skilled labour-force participants, which can retard economic development; additionally, with more learners in each grade at school, school systems can suffer strain. However, when learners are ill and are absent from school for extended periods of time, they might have to repeat grades if they are unable to catch up or pass key progression subjects.

The present study has found that adolescents have a high burden of infectious disease, with NCDs and mental illnesses increasing over time. This finding is consistent with other studies that have found a high prevalence of HIV and other sexually transmitted diseases among 10 - 19-year-olds in the country. ${ }^{[17,18]}$ These studies conclude that sexually transmitted diseases are closely related to risky behaviours, which adolescents are not knowledgeable about, or are unable to protect themselves from. ${ }^{[18,19]}$ Infectious diseases such as TB and diarrhoea can be contracted from adult and child family members with whom adolescents share living quarters and household resources, ${ }^{[20,21]}$ thus also making these diseases difficult to prevent at an individual level.

The increasing prevalence of NCDs is also found to be consistent with existing literature in the country which shows that, overall, the SA population is increasingly affected by hypertension, diabetes and cancer. ${ }^{[22]}$ This and other literature contends that the increase in NCDs in SA coincides with behavioural and lifestyle changes regarding stress, lack of physical exercise and the adoption of deficient diets. ${ }^{[22-24]}$ The increasing levels of mental illness could be attributed to improvements made in the recognition and reporting of depression and other mental diseases in the region. ${ }^{[25,26]}$

The study is subject to a few limitations. Firstly, causation between illness and repeating a school grade could not be determined using the cross-section data. Secondly, diseases are self-reported and, as such, many NCDs and mental illnesses that adolescents have not been formally diagnosed with could have been missed. Finally, certain diseases have colloquial names that were not included in the survey (for example, diabetes is sometimes called 'sugar ${ }^{\text {'[27] }}$ ), and thus adolescents who know these diseases by their colloquial names only might not report having them. 
However, there are also some strengths to this study: (i) the survey collected information on an extensive number of diseases, which creates a more holistic profile of adolescent health challenges; (ii) the sample of adolescents who participated in the survey is large, and allows a robust analysis of the topic; and (iii) the study found a relationship between disease prevalence and school repetition, which has not been examined elsewhere in the country, to the best of the authors' knowledge.

\section{Conclusion}

The burden of infectious, non-communicable and mental diseases compromises the healthy development of adolescents. For this reason, approaches to disease prevention and treatment cannot be disease specific. There needs to be a comprehensive and inclusive approach that includes a wide array of diseases simultaneously. Furthermore, efforts to prevent learners from repeating grades owing to illness need to be devised. Current strategies that promote grade progression may do more harm than good to the psychological development of adolescents, and have implications for SA's economic growth.

Future research on the relationship between disease and transition to adulthood should examine the length of absenteeism contributing to grade repetition, and the socioeconomic determinants, including access to healthcare. These contributions will assist policy in creating educational guidelines to assist affected adolescents. Further research on other transitions to adulthood, including age at first marriage and labour market entry, would create a better profile of all the challenges that adolescents with disease face.

Acknowledgements. The support of the DST-NRF Centre of Excellence $(\mathrm{CoE})$ in Human Development for this research is hereby acknowledged. Opinions expressed and conclusions arrived at are those of the authors, and are not necessarily to be attributed to the CoE in Human Development. The authors gratefully acknowledge the support of the Demography and Population Studies Programme, Schools of Public Health and Social Sciences, Faculties of Health Sciences and Humanities, University of the Witwatersrand, Johannesburg, SA.

Author contributions. NdW conceptualised and led the study. Specifically, she wrote the introduction, methods and discussion for the paper. She also responded to reviewer comments. SF cleaned and analysed the data and wrote up the results section.

Funding. DST-NRF Centre of Excellence in Human Development Opportunity Grant, of which NdW was an awardee.

Conflicts of interest. None.

1. Filmer D, Fox L. Youth Employment in Sub-Saharan Africa. Washington, DC: World Bank Publications; 2014.

2. Gove A. What we are learning about early education in sub-Saharan Africa. J Res Edu Effect 2017:10(3):530-534. https://doi.org/10.1080/19345747.2017.1335091

3. Muthuri SK, Francis CE, Wachira L-JM, et al. Evidence of an overweight/obesity transition among school-aged children and youth in Sub-Saharan Africa: A systematic review. PLoS One 2014;9(3):e92846. https://doi.org/10.1371/ journal.pone.0092846

4. Hargreaves JR, Bonell CP, Boler T, et al. Systematic review exploring time trends in the association between educational attainment and risk of HIV infection in sub-Saharan Africa. AIDS 2008;22(3):403-414. https://doi.org/10.1097/ QAD.0b013e3282f2aac3

5. Sawyer SM, Afifi RA, Bearinger LH, et al. Adolescence: A foundation for future health. Lancet 2012;379(9826):1630-1640. https://doi.org/10.1016/S01406736(12)60072-5
6. Statistics South Africa. Census 2011: A Profile of Educational Enrolment, Attainment and Progression in South Africa, 2011. Pretoria: Statistics South Africa, 2012

7. Cluver L, Boyes M, Orkin M, Sherr L. Poverty, AIDS and child health: Identifying highest-risk children in South Africa. S Afr Med J 2013;103(12):910 915. https://doi.org/10.7196/samj.7045

8. Wood K, Jewkes R. Violence, rape, and sexual coercion: Everyday love in a South African township. Gender Develop 1997;5(2):41-46.

9. Patel V, Flisher AJ, Hetrick S, McGorry P. Mental health of young people: A global public-health challenge. Lancet 2007;369(9569):1302-1313. https://doi. org/10.1016/S0140-6736(07)60368-7

10. Esch P, Bocquet V, Pull C, et al. The downward spiral of mental disorders and educational attainment: A systematic review on early school leaving. BMC Psychiatry 2014;14(1):237. https://doi.org/10.1186/s12888-014-0237-4

11. Ohrt J, Webster L, De La Garza M. The effects of a success skills group on adolescents' self-regulation, self-esteem, and perceived learning competence. Professional School Counseling 2014;18(1):169-178. http://doi. org/10.5330/2156-759X-18.1.169

12. Grossen S, Grobler AA, Lacante M. Repeated retention or dropout? Disputing Hobson's choice in South African township schools. S Afr J Edu 2017;37(2):111. http://doi.org/10.15700/saje.v37n2a1367

13. Statistics SA. Morbidity and mortality patterns among the youth of South Africa, 2013. Pretoria: Statistics South Africa, 2015.

14. Coudé FX, Mignot C, Lyonnet S, Munnich A. Early grade repetition and inattention associated with neurofibromatosis type 1. J Att Dis 2007;11(2):101105. https://doi.org/10.1177/1087054707299398

15. Williams PL, Storm D, Montepiedra G, et al. Predictors of adherence to antiretroviral medications in children and adolescents with HIV infection. Pediatrics 2006;118(6):e1745-e1757. https://doi.org/10.1542/peds.2006-0493

16. Walker SP, Wachs TD, Gardner JM, et al. Child development: Risk factors for adverse outcomes in developing countries. Lancet 2007;369(9556):145-157. https://doi.org/10.1016/S0140-6736(07)60076-2

17. Pettifor AE, Rees HV, Kleinschmidt I, et al. Young people's sexual health in South Africa: HIV prevalence and sexual behaviors from a nationally representative household survey. AIDS 2005;19(14):1525-1534.

18. Zuma K, Shisana O, Rehle TM, et al. New insights into HIV epidemic in South Africa: Key findings from the National HIV Prevalence, Incidence and Behaviour Survey, 2012. Afr J AIDS Res 2016;15(1):67-75. https://doi.org/10.2 989/16085906.2016.1153491

19. Cluver LD, Orkin MF, Yakubovich AR, Sherr L. Combination social protection for reducing HIV-risk behavior amongst adolescents in South Africa. J Acq Imm Def Syndr 2016;72(1):96.

20. Longini Jr IM, Koopman JS. Household and community transmission parameters from final distributions of infections in households. Biometrics 1982:115-126

21. Cowling BJ, Fung RO, Cheng CK, et al. Preliminary findings of a randomized trial of non-pharmaceutical interventions to prevent influenza transmission in households. PLoS One 2008;3(5):e2101. https://doi.org/10.1371/journal. pone.0002101

22. Mayosi BM, Flisher AJ, Lalloo UG, Sitas F, Tollman SM, Bradshaw D. The burden of non-communicable diseases in South Africa. Lancet 2009;374(9693):934947. https://doi.org/10.1016/S0140-6736(09)61087-4

23. Dalal S, Beunza JJ, Volmink J, et al. Non-communicable diseases in sub-Saharan Africa: What we know now. Int J Epidemiol 2011;40(4):885-901. https://doi. org/10.1093/ije/dyr050

24. Lee I-M, Shiroma EJ, Lobelo F, et al. Effect of physical inactivity on major noncommunicable diseases worldwide: An analysis of burden of disease and life expectancy. Lancet 2012;380(9838):219-29. https://doi.org/10.1016/S01406736(09)61087-4

25. Corrigan PW, Morris SB, Michaels PJ, Rafacz JD, Rüsch N. Challenging the public stigma of mental illness: A meta-analysis of outcome studies. Psych Services 2012;63(10):963-973. https://doi.org/10.1176/appi.ps.201100529

26. Kutcher S, Wei Y, Gilberds H, et al. Evaluating community health care providers knowledge and self-confidence in the identification, diagnosis and treatment of adolescent Depression in Tanzania. Arch Depress Anxiety 2016;2(1):10261030.

27. Azevedo M, Alla S. Diabetes in sub-saharan Africa: Kenya, Mali, Mozambique, Nigeria, South Africa and Zambia. Int J Diabetes Dev Ctries 2008;28(4):101 108. https://doi.org/10.4103/0973-3930.45268 